Revista Brasil. Bot., V.25, n.2, p.117-127, jun. 2002

\title{
Ovule ontogeny of Tabebuia pulcherrima Sandwith (Bignoniaceae): embryo sac development
}

\author{
NELSON S. BITTENCOURT JR. ${ }^{1,3}$ and JORGE E.A. MARIATH ${ }^{2}$
}

(received: January 24, 2001; accepted: January 16, 2002)

\begin{abstract}
Ovule ontogeny of Tabebuia pulcherrima Sandwith (Bignoniaceae): embryo sac development). The chalazal megaspore develops in a Polygonum-type embryo sac. The amyloplast-rich endothelium is partially degraded during the expansion of the micropylar portion of the megagametophyte. Organization of the mature embryo sac is determined by the patterns of vacuolation, nuclear migration, spindle orientation and cellularization. The egg cell is slightly chalazal in relation to the synergids, and its micropylar end does not touch the micropylar channel. At the chalazal pole of the egg apparatus, the common walls between the synergids, the egg and central cells, despite their tenuity, are present in the mature megagametophyte. The polar nuclei do not fuse before fertilization and the antipodals are persistent until the first stages of endosperm formation. The taxonomic significance of some embryological characters for the Bignoniaceae is discussed.
\end{abstract}

RESUMO - (Ontogenia do óvulo de Tabebuia pulcherrima Sandwith (Bignoniaceae): desenvolvimento do saco embrionário). O megásporo calazal origina um saco embrionário tipo Polygonum. O endotélio rico em amiloplastos é parcialmente degradado durante a expansão da porção micropilar do megagametófito. A organização do saco embrionário maduro é determinada pelos padrões de vacuolação, migração nuclear, orientação dos fusos mitóticos e celularização. A oosfera é ligeiramente calazal em relação às sinérgides e sua extremidade micropilar não estabelece contato com o canal micropilar. Na porção calazal do aparato oosférico, as paredes comuns entre as sinérgides, a oosfera e a célula média, embora muito tênues, estão presentes no saco embrionário maduro. Os núcleos polares não se fundem antes da fecundação e as antípodas persistem até o início do desenvolvimento do endosperma. O significado taxonômico de alguns caracteres embriológicos para a família Bignoniaceae é discutido.

Key words - Embryo sac, megagametogenesis, female germ unit, cellularization, Tabebuia

\section{Introduction}

Studies of the female gametophyte in species of Bignoniaceae are very scarce. The majority and the most important of them deal with general aspects of the embryology of the species studied, giving only some superficial information about embryo sac development. The first reported study of the embryo sac ontogeny in a Bignoniaceae was made by Guignard (1882 apud Schnarf 1931) in Bignonia capensis (= Tecoma capensis). Subsequent studies were performed in Bignonia venusta (= Pirostegia venusta) (Duggar 1899), Bignonia tweediana, B. bungei, Campsis radicans, $C$. chinensis, Catalpa bignonioides, Crescentia macrophylla, Incarvillea olgae, Jacaranda mimosifolia, Phaedrantyus sp., Tecoma sambucifolia (Mauritzon

1. Universidade Estadual de Campinas, Departamento de Botânica, Caixa Postal 6109, 13083-970 Campinas, SP, Brazil.

2. Universidade Federal do Rio Grande do Sul, Departamento de Botânica, Laboratório de Anatomia Vegetal, Av. Bento Gonçalves 9500, Prédio 43423, Sala 206, 91501-970 Porto Alegre, RS, Brazil. jorge.mariath@ufrgs.br

3. Corresponding author: nesbitte@unicamp.br
1935), Bignonia megapotamica (Swamy 1941), Jacaranda mimosifolia, Parmentiera cereifera, Kigelia pinnata, Tecoma stans (Govindu 1950), Oroxilum indicum (Ghatak 1956), Tabebuia rosea, Millingtonia hortensis, Dolichandrone falcata, Heterophragma adenophylum, Stereospermum chelonoides (Mehra \& Kulkarni 1985) and Tabebuia ochracea (Bittencourt Jr. 1992). Schnarf (1931), Davis (1966) and Johri et al. (1992) organized taxonomically the existing literature.

Nowadays, much literature exists about the structure and development of the megagametophyte in angiosperms. However, details about nuclear migration during the free-nuclear stages of the embryo sac, expansion and organization of its vacuome, and the process of cellularization have received less attention (Kapil \& Bhatnagar 1981, Cass et al. 1985, Bhandari \& Chitralekha 1989). According to Newcomb (1973) and Kapil \& Bhatnagar (1981), the scarcity of this kind of information may be due to the difficulty to collect suitable material at critical stages. But the study of these aspects of embryo sac development, in several particular cases, is essential for a more comprehensive understanding of structural and functional organization of the mature megagametophyte. 
Different phases of the embryo sac development of Tabebuia pulcherrima Sandwith were presently investigated, not only to contribute to the understanding of the female gametophyte organization in flowering plants, but equally to supply embryological features for use in Bignoniaceae taxonomy.

\section{Material and methods}

Collection and processing of Tabebuia pulcherrima Sandwith for light microscopic analysis was done as already described in Bittencourt Jr. \& Mariath (2002). Successive stages of embryo sac development were inferred by the length of the ovary, and several samples of each length were examined. All ovaries were transversely sectioned in less than $2 \mathrm{~mm}$ thick slices, in order to ensure penetration of the fixative. After the embedding in historesin, the samples were sectioned in microtome, in 1 to $4 \mu \mathrm{m}$ thick transverse sections.

\section{Results}

The development of the embryo sac in T. pulcherrima is of the Polygonum type. During the embryo sac mother cell nucleus' first acytokinetic mitosis, the metaphasic plate is always perpendicular to the longitudinal axis (figure 1). The vacuome tends to fragment and, immediatelly after karyokinesis, the nuclei of the two nucleated embryo sac begin to move to opposite poles, while a central vacuole grows between them (figures 2, 3). Remnants of the micropylar megaspores are squeezed at the micropylar end of the embryo sac (figures 1,2).

The nucellar epidermis is gradually disorganized, but some of its cells persist around the base of the embryo sac (figure 3). A slight thickening of the cuticle at the outer periclinal walls of the persisting nucellar epidermal cells was observed. The central vacuole which from this stage on will originate the central cell vacuome of the maturing megagametophyte - enlarges significantly, accumulating a fibrous-granulated substance similar to the one mentioned for the polar vacuoles of the embryo sac mother cell (Bittencourt Jr. $\&$ Mariath 2002). The nuclei start to occupy the micropylar and chalazal poles of the megagametophyte. The chalazal portion of the embryo sac is projected slightly into the chalaza, without disturb its cells. Usually, a great part of the chalazal vacuole persists between the chalazal nucleus and the chalazal wall of the two-nucleated embryo sac. At the micropylar portion, the expanding megagametophyte not only absorbs the remnants of the micropylar megaspores, but also begins to occupy the space of the degenerating endothelial cells. The micropylar nucleus is usually positioned very close to the distal wall of the megagametophyte, with only small remaining fragments of the micropylar vacuole surrounding it (figures 3,4).

The micropylar region of the embryo sac expands for the sides, as well as upward, invading the proximal portion of the micropylar channel (figures 4, 5). Remnants of cell walls from the degenerated nucellar epidermis and endothelium accumulate around the embryo sac, forming a strongly pectinized envelope. At the middle and chalazal regions of the megagametophyte, the endothelial cells are not disrupted, so that the narrow space between the disorganized nucellar epidermis and the endothelium is preserved and the megagametophyte as a whole becomes clavae-shaped. Even after ovule fecundation, the endothelial cells around the narrowed portion of the embryo sac stay undisturbed, with dense cytoplasm, and frequently presenting mitotic divisions.

The two nuclei of the embryo sac simultaneously undergo the second acytokinetic mitosis (figure 5). The metaphasic plate of the chalazal nucleus is perpendicular to the longitudinal axis of the megagametophyte in all observed samples, while in the micropylar nucleus it is oblique or almost parallel to the axis. After karyokinesis, the two chalazal nuclei are positioned on the longitudinal axis of the embryo sac, and small irregular vacuoles begin to form between them (figures 6,7). The two micropylar nuclei are simply rearranged, becoming approximately aligned with the longitudinal axis.

At the tetranucleate stage, the distal portion of the megagametophyte invades great part of the micropylar channel. However it does not reach the external side of the ovule, remaining inside the integument (figure 6,7). The fibrous-granulated content of the vacuome gradually disappears. Starch grains, intensely synthesized by the endothelial cells, persist after such cells been squeezed, so that these starch grains accumulate in the embryo sac envelope, giving it a wavy contour.

The third and last karyokinesis of the embryo sac takes place in the four nuclei at the same time (figures 8-10). Although the chalazal portion of the megagametophyte is narrowed, the spindles can be guided in the $\mathrm{T}$ configuration, i.e. with the metaphasic plates of the proximal and distal chalazal nuclei parallel and perpendicular to the longitudinal axis of the 


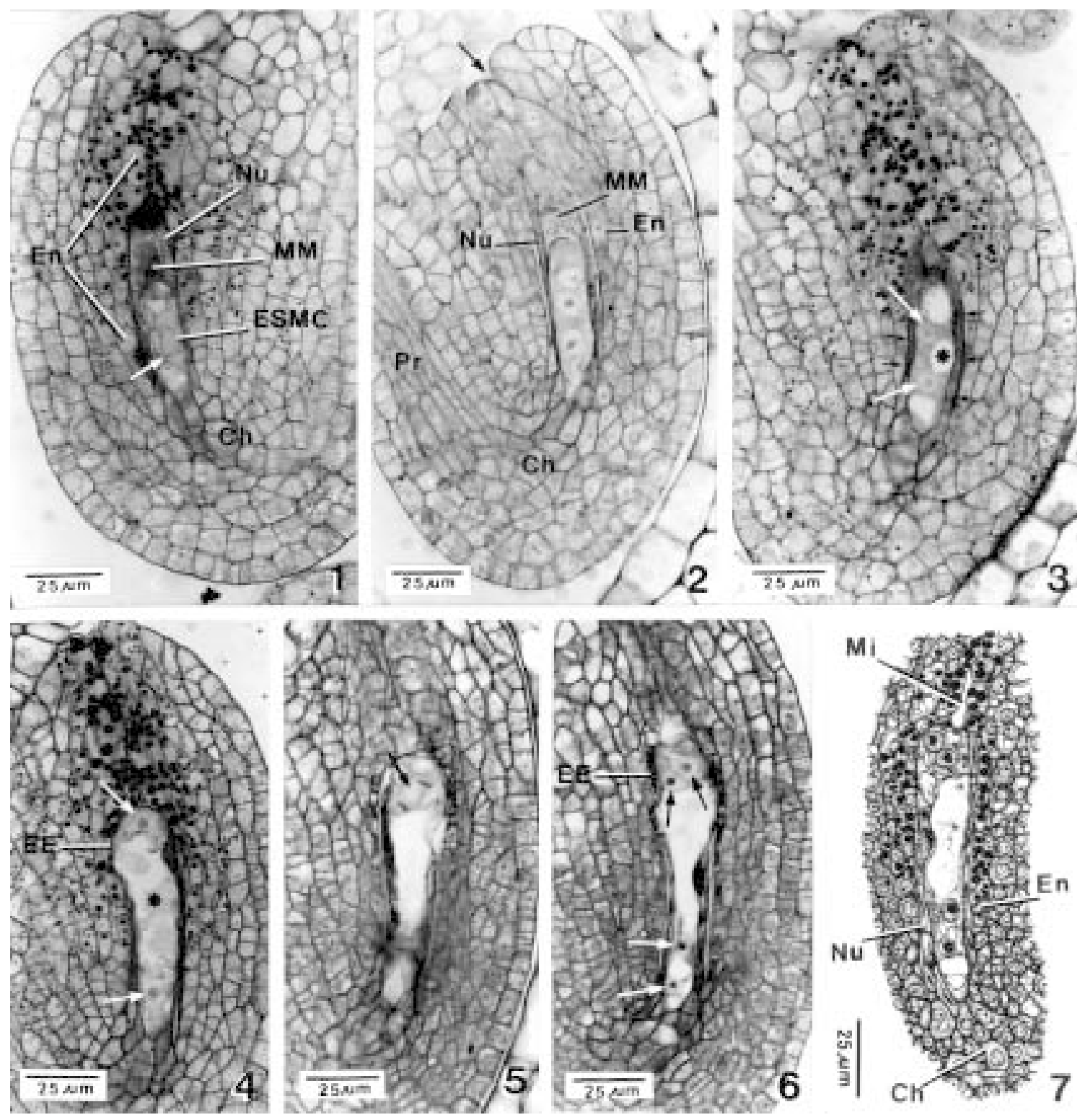

Figures 1-7. Longitudinal sections of the ovule showing several stages of the embryo sac development. 1. Embryo sac mother cell at first acytokinetic mitosis. The arrow indicates metaphasic plate chromosomes. 2 . The free-nuclear embryo sac just after first karyokinesis. Arrow indicates micropyle. 3. Two-nucleated embryo sac at the beginning of the central vacuole (asterisk) expansion. White arrows indicate nuclei. Black arrows indicate the site of cutinization on the nucellar epidermis. 4. Late 2-nucleated embryo sac. Arrows indicate nuclei. Asterisk indicates expanded central vacuole. 5. Free-nuclear embryo sac at second karyokinesis (anaphase). Arrow indicates mitotic micropylar nucleus (the chalazal nucleus is not visible in this plane of section). 6. Four-nucleated embryo sac. Black arrows indicate micropylar nuclei. White arrows indicate chalazal nuclei. 7. Drawing reconstituting the 4-nucleated embryo sac vacuome. 1, 3 and 4 stained with PAS and Sudan black B. Dark-spherical organelles are amyloplasts. 2, 5 and 6 stained with toluidine blue $\mathrm{O}$ and acid fuchsin. Ch: chalaza, EE = embryo sac envelope, $\mathrm{Em}=$ endothelium, ESMC = embryo sac mother cell, $\mathrm{MM}=$ degenerated micropylar megaspores, $\mathrm{Mi}=$ micropylar channel, $\mathrm{Nu}=$ nucellar epidermis, $\mathrm{Pr}=$ procambium.

megagametophyte, respectively. Alternatively, the proximal spindle can be positioned with the metaphasic plate in an oblique, almost perpendicular position in relation to the axis. The distally positioned chalazal mitotic nucleus originates the chalazal polar nucleus and the nucleus of one of the mature embryo sac antipodals. The two other antipodal nuclei are derived from the proximally positioned chalazal mitotic nucleus. On the other hand, at the micropylar portion of the megagametophyte, the spindles were only observed in the $\perp$ configuration, i.e. with the metaphasic plates of the distal and proximal micropylar nucleus 

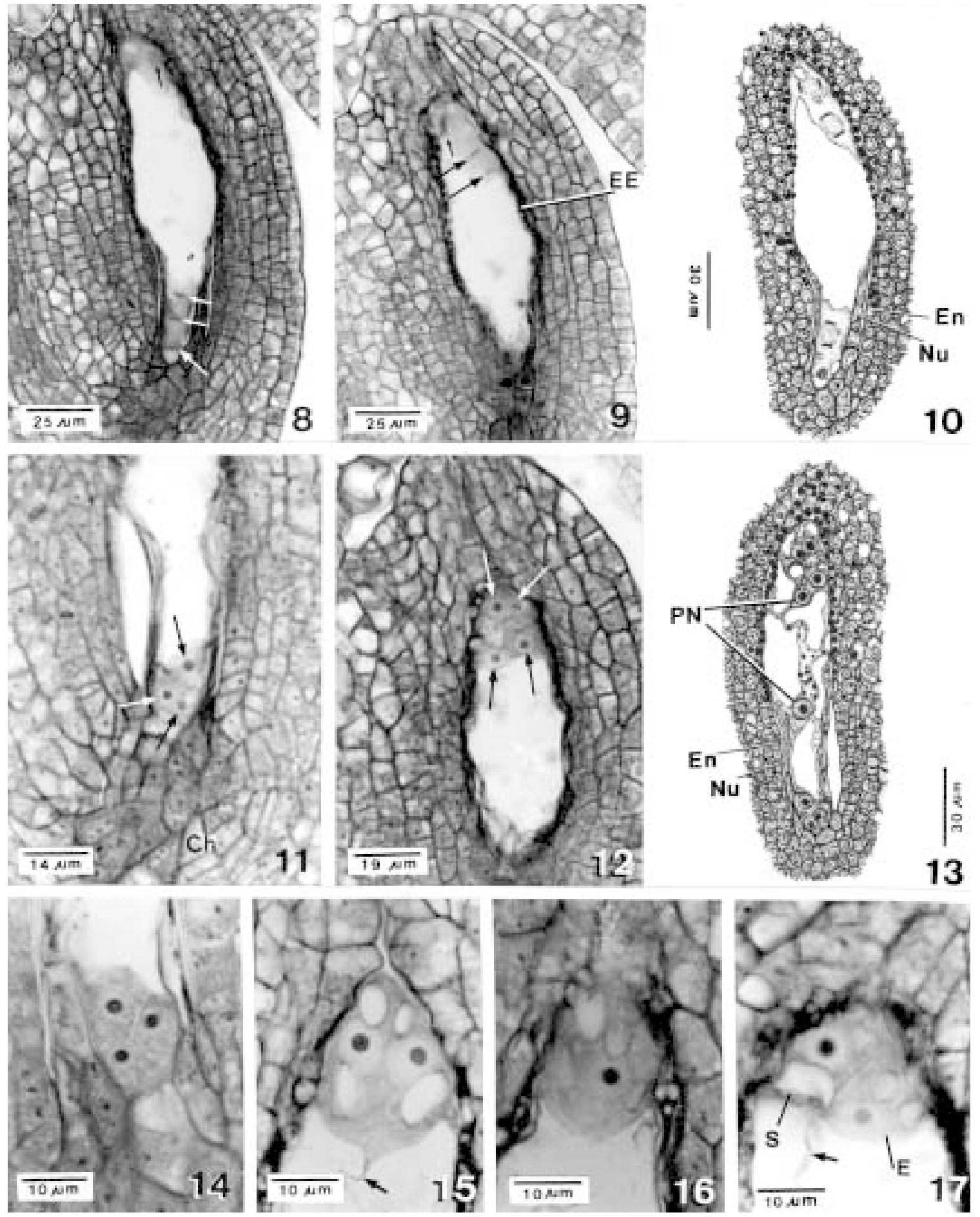

Figures 8-17. Longitudinal section of the ovule showing several stages of the embryo sac development. 8 and 9. Serial sections of an ovule at third karyokinesis (anaphase). Black shorter arrows indicate chromosomes of the distal micropylar nucleus; black bigger arrows indicate chromosomes of the proximal micropylar nucleus. White shorter arrows indicate chromosomes of the distal chalazal nucleus; white bigger arrow indicates chromosomes of the proximal chalazal nucleus. 10. Drawing reconstruction of the whole free-nuclear embryo sac at the third karyokinesis. 11 and 12. Embryo sac immediately after third karyokinesis. 11. Chalazal end. The arrows indicate the antipodal nuclei (the chalazal polar nucleus is not visible in this section). 12. Micropylar end. The arrows indicate the four-micropylar nuclei. 13. Drawing reconstruction of the whole 8-nucleated embryo sac. 14-17. Longitudinal sections of young cellular embryo sac. 14. Antipodals. 15. The two synergids side by side. 16. Egg cell. 17. Egg and one synergid side by side. The arrows in 15 and 17 indicate cytoplasmic strands in the central cell. In all photomicrographs, the sections were stained with toluidine blue $\mathrm{O}$ and acid fuchsin. $\mathrm{Ch}=$ chalaza, $\mathrm{E}=\mathrm{egg}$ cell, $\mathrm{EE}=$ embryo sac envelope, $\mathrm{Em}=$ endothelium, $\mathrm{Nu}=$ nucellar epidermis, $\mathrm{PN}=$ polar nuclei, $\mathrm{S}=$ synergid. 
approximately parallel and perpendicular to the longitudinal axis of the embryo sac, respectively. The proximal micropylar mitotic nucleus is usually positioned sidewards, the opposite side being occupied by the micropylar end of the central vacuole (figures 9 , 10). The distally positioned micropylar mitotic nucleus gives origin to the nuclei of the two synergids, the proximally positioned one gives origin to the micropylar polar nucleus and to the egg cell nucleus.

The third and last mitotic division of the megagametogenesis results in an embryo sac with eight nuclei and seven cells (figures 11-17). Apparently the processes of karyokinesis and cytokinesis are quite continuous because no completely non-cellular 8 -nucleated embryo sac was observed. The central vacuole in this stage begins to become separated in irregular compartments due to the formation of cytoplasmic strands and, inside these strands, numerous amyloplasts grow (figure 13). The process of cellularization seems to be faster at the chalazal region because in embryo sacs in which the cell walls of the egg apparatus are not yet differentiated, the walls that separate the antipodals are already clearly visible.

Antipodals position after cytokinesis is very variable. They can be placed in a linear, triangular or several intermediate arrangements (figure 14). The young antipodals have dense cytoplasm with tiny vacuoles. Invariably, the chalazal polar nucleus begins to move to the center of the embryo sac before the complete cellularization of the antipodals (figure 13). In the recently formed egg apparatus, the synergids and egg cell are triangularly arranged (figures 15-17). These cells inherit small vacuoles already existing in the micropylar portion of the embryo sac before cellularization. Although the micropylar polar nucleus may start to move away from the egg apparatus during cellularization, it commonly does so after cytokinesis is completed (figures 12,13).

Immediately after cellularization, the egg cell can be easily distinguished from the synergids. In a young egg cell, the nucleus and most of the cytoplasm are located at the chalazal pole, with one or more vacuoles at the micropylar pole (figures 16, 17). In the synergids, the position of the nucleus is central to slightly micropylar. Both cytoplasmatic poles of a synergid contain vacuoles, and the chalazal vacuole usually is larger than the micropylar one (figure 15). The position of the three cells in the egg apparatus is variable. In some middle longitudinal sections of the embryo sac, the egg cell is seen beside one of the synergids (figure 17); in others the two synergids are visible (figure 15), or just the egg cell is seen (figure 16). The egg cell and the synergids are pear-shaped, wider in the proximal (chalazal) portion, more narrowed in the distal (micropylar) portion, with a dense cytoplasm. However, the micropylar extremity of the egg cell does not reach the micropyle and its chalazal portion is a little salient in relation to the synergids. Therefore the egg cell position in the embryo sac is lateral and slightly more chalazal than the synergids (figure 17).

After the organization of the egg apparatus, the synergids and the egg cell expand considerably, becoming elongated and invading a great part of the micropylar portion of the central cell (figures 18-20). Such growth is accompanied by vacuolar expansion that, in the case of the synergids, is more accentuated in the chalazal vacuole. In the mature megagametophyte the wall structure is complex, due to its compactness close to the walls of collapsed cells of the integument and nucellar epidermis (figures 21-23). In the micropylar area, where the embryo sac expands absorbing the endothelium, the wall is thicker (embryo sac envelope), attenuating in the chalazal area, where the cells of the nucellar epidermis, although disorganized, are not totally deformed (figures 21-23, 26). The cuticle of the nucellar epidermis in this region remains relatively thick and quite visible in sections stained with Sudan black B (figure 22). Only the distal portion of the egg apparatus stays in direct contact with the embryo sac envelope. In the middle and proximal regions, a narrow space, filled with cytoplasm of the central cell, separates the embryo sac envelope from the egg apparatus (figures 24, 25).

At the chalazal pole of the egg apparatus the common walls of the synergids, the egg cell and the central cell become very thin (figures 24-26); however they are PAS-positive and do not present discontinuities. The cytoplasm of the synergids and egg cell remain dense and numerous amyloplasts differentiate, especially around the nucleus (figures 22-25). However, in the egg cell the micropylar vacuole occupies almost the whole cell, leaving only a small amount of cytoplasm around the nucleus, where small vacuoles are present (figures 23, 25). At the micropylar portion of the synergids, a filiform apparatus grows as a strongly PASpositive wall thickening between both cells and where they are in direct contact with the inner end of the micropyle (figures 22, 24, 26). No wall ingrowth of the filiform apparatus was seen, even at the highest magnification of the microscope. 

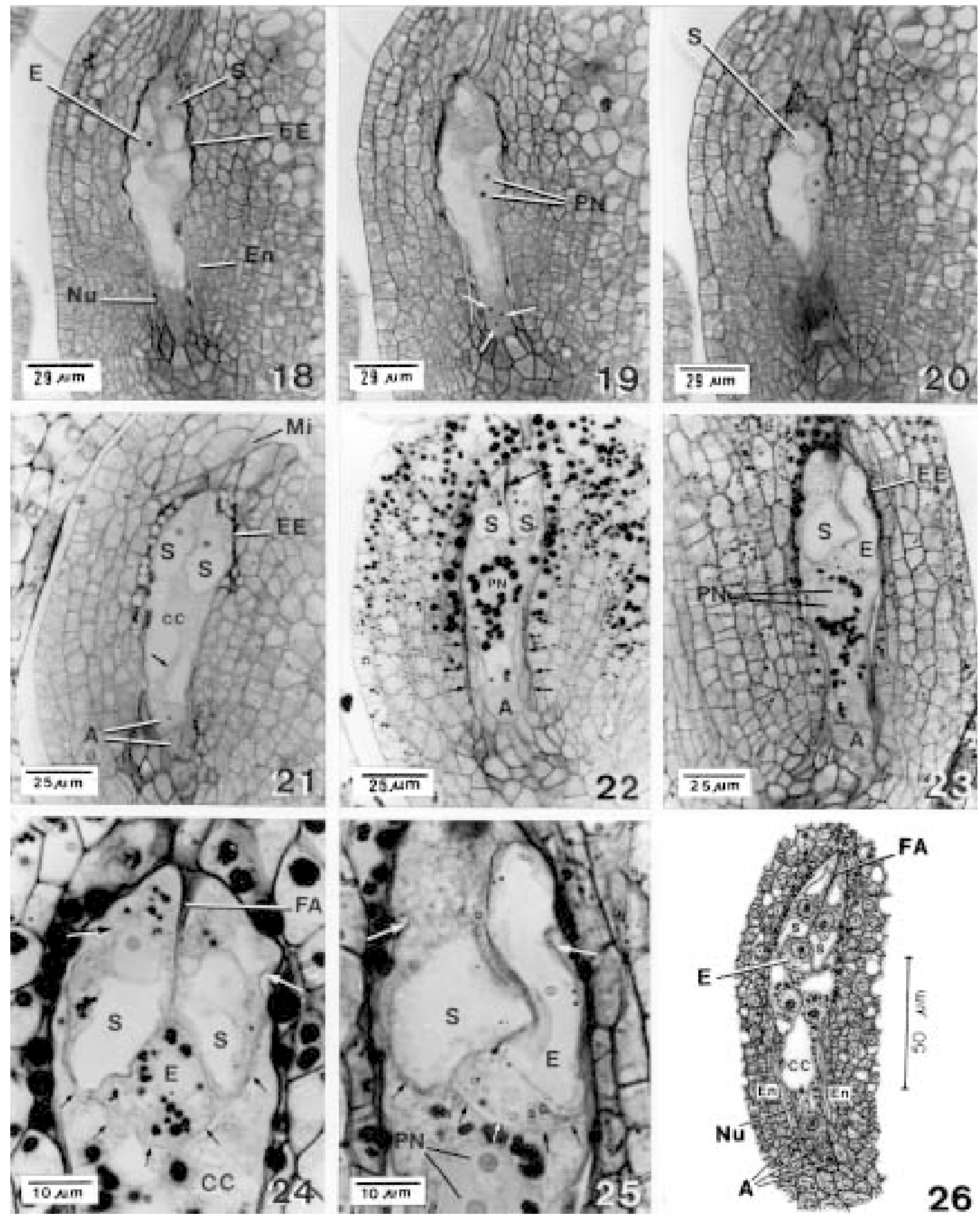

26

Figures 18-26. Longitudinal section of the ovule showing several stages of the embryo sac development. 18-20. Serial sections of an ovule showing the embryo sac near the maturity. Arrows indicate antipodals. Staining: toluidine blue O and acid fuchsin. 21. Mature embryo sac stained with toluidine blue $\mathrm{O}$ and acid fuchsin. The arrow indicates a cytoplasmic strand in the central cell. 22 and 23. Mature embryo sac stained with PAS and Sudan black B. 22. Synergids showed side by side. The shorter arrows indicate the nucellar epidermis thick cuticle. The bigger arrow indicates the filiform apparatus. 23. Synergid and egg cell showed side by side. 24 and 25. Micropylar end of the mature embryo sac (stained with PAS and Sudan black B). The shorter arrows indicate the common wall of the central cell and egg apparatus. The bigger arrows indicate hooks. 24. Showing the synergids side by side. 25 . Showing one synergid and the egg cell side by side. The dark-spherical organelles in 22-25 are amyloplasts. 26. Drawing reconstruction of the whole mature embryo sac. $\mathrm{A}=$ antipodals, $\mathrm{CC}=$ central cell, $\mathrm{E}=$ egg cell, $\mathrm{EE}=$ embryo sac envelope, $\mathrm{Em}=$ endothelium, $\mathrm{FA}=$ filiform apparatus, $\mathrm{Mi}=$ micropyle, $\mathrm{Nu}=$ nucellar epidermis, $\mathrm{PN}=$ polar nuclei, $\mathrm{S}=$ synergid. 
In the central cell, the cytoplasmic density increases (figures 21,23) and numerous amyloplasts are continually produced. The central cell amyloplasts are larger than the amyloplasts of other cells of the embryo sac, and they tend to accumulate around the polar nuclei. The vacuome tends to fragment in small vacuoles of irregular shapes (figures 21, 22, 26). The polar nuclei expand, their nucleoli become prominent and frequently present nucleolar vacuoles. The polar nuclei migrate to a central position in the embryo sac, becoming very close to each other, but do not fuse (figures 23, 25, 26). Preliminary observations of the fertilization process in the megagametophyte suggest that the fusion of the polar nuclei only happens after the pollen tube penetrates the embryo sac, because in ovaries containing fecundated and non-fecundated ovules, the last ones showed non-fused polar nuclei. Due to the expansion of the egg apparatus, the chalazal pole of the egg cell, where its nucleus is found, approaches closely the polar nuclei in the mature embryo sac (figures 25, 26).

The antipodal cells stay viable until the maturity of the megagametophyte, presenting a modest cellular expansion (figures $21,22,26$ ). The cytoplasmic density of the antipodals is greater than in all the other cells of the embryo sac. Small vesicles of irregular shapes are abundant in the cytoplasm. In the nucleus, the nucleolus becomes quite conspicuous. The first signs of nuclear pycnosis appear only at the last stage of maturation, when the embryo sac is ready to be fertilized.

During the whole megasporogenesis and megagametogenesis, but especially in the last ontogenetic stages of the embryo sac - between the tetranucleate stage and the mature megagametophyte there is no strict synchrony of ovule maturation, and ovules containing megagametophytes in different developmental stages can be found in a same transverse section of the ovary. At anthesis, most of the megagametophytes are mature (figure 26).

During the maturation of the embryo sac, at the flanks (integument) and chalazal end of the ovule, periclinal divisions occur in the underlying cells of the epidermis. Consequently, the ovule becomes discshaped, and this is the first step to the wing formation in the seed of Tabebuia.

\section{Discussion}

The following features observed in T. pulcherrima are common for all Bignoniaceae studied up to now: the embryo sac elongation during free-nuclear stages; lateral enlargement of its micropylar region accompanied by disorganization and absorption of the adjacent nucellar epidermis and endothelial cells; megagametophyte invasion of the micropyle proximal portion; partial preservation of some cells of the nucellar epidermis and maintenance of an active differentiated endothelium (when present) adjacent to the lateral walls of the embryo sac chalazal region (Mauritzon 1935, Swamy 1941, Govindu 1950, Ghatak 1956, Mehra \& Kulkarni 1985, Galati \& Strittmatter 1999). Although it has been held for many years that nucellar (and endothelial) cells which degenerate do so as a consequence of mechanical pressure, more recent studies indicate that degeneration of these cells is a genetically controlled phenomenon of autolysis rather than a result of mechanical pressure from the growing megagametophyte (Tilton \& Lersten 1981).

Folsom \& Cass $(1989,1990)$ pointed out that, in soybean, the development of the tetranucleate embryo sac is guided by the giant central vacuole, which limits the nuclear movements, and control in this way the subsequent ontogenetic events. The present observations indicate that, not only the central vacuole, but the whole vacuome of the embryo sac is involved in the control of the subsequent ontogenetic events and in the organization of the mature female gametophyte of $T$. pulcherrima. This can be inferred by the following observations: (1) the vacuolation between the two chalazal nuclei at the tetranucleate stage; (2) the lateral position of the proximal micropylar nucleus, imposed by the micropylar end of the central vacuole during the transition between the 4- and 8-nucleate stages; (3) the inheritance of vacuoles, already existing at the micropylar pole of the embryo sac before cellularization, by the cells of the recently-formed egg apparatus; (4) the concomitant expansion of the egg apparatus and of the vacuoles of the synergids and egg cell. Moreover, the expansion of the egg apparatus and the restriction of the egg cell nucleus into the chalazal pole by the egg cell vacuole, act together to approximate the polar nuclei and the egg cell nucleus, which seems to be important for the process of double fecundation (Huang \& Russell 1992).

In the tetranucleate stage, the two micropylar nuclei shift their position, becoming parallel to the longitudinal axis of the megagametophyte, while the distal chalazal nucleus moves slightly in direction to the center of the embryo sac. Folsom \& Cass (1990) admitted that, in soybean, changes of position of the chalazal nuclei are related with the elongated shape that the chalazal portion 
of the embryo sac acquires in the tetranucleate stage. However, they did not point out any possible relationship between the positional shifting of the micropylar nuclei and the form of the micropylar portion of the gametophyte. The authors demonstrated that one of the micropylar nuclei stays in distal position, originating after the third mitotic cycle the nuclei of the two synergids, while the other moves in chalazal direction, originating the micropylar polar nucleus and the nucleus of the egg cell. Therefore such position changes determine the destiny of both micropylar nuclei. However, Bhandari \& Chitralekha (1989) observed that both micropylar nuclei stay at the same level, in the wide micropylar pole of the 4-nucleate embryo sac of Ranunculus scleratus. In the tetranucleate megagametophyte of Tabebuia pulcherrima, not only the destiny of the micropylar nuclei is determined by the chalazal movement of one of them, but the destiny of the chalazal nuclei is at least partially determined by the micropylar movement of the distal chalazal nucleus, independently of this movement to be or not related with the narrowed shape of the embryo sac chalazal portion. In fact the destiny of the chalazal nuclei begin to be defined still during the second karyokinesis, as in that stage the metaphasic plate of the proximal mitotic nucleus seems to be always perpendicular to the longitudinal axis of the embryo sac.

The positioning of the mitotic spindles of the third karyokinesis, as much in the chalazal as in the micropylar portion, seem to determine the arrangement of the antipodals and egg apparatus. The last karyokinetic cycle and cytokinesis are intimately associated, being the cellularization initiated at the chalazal end. Folsom \& Cass (1989) observed the same in soybean. In other species, cytokinesis is processed simultaneously in both the chalazal and micropylar poles (Bhandari \& Chitralekha 1989). This is in contradiction with the statement of Huang \& Russell (1992) according to whom cellularization at both the chalazal and micropylar poles are always simultaneous. In several angiosperms, the speed with which the cell walls are formed after the last mitotic cycle makes it difficult to follow step by step the cellularization process. This has been pointed as a cause of the lack of information about that critical ontogenetic stage of the female gametophyte (Kapil \& Bhatnagar 1981, Bhandari \& Chitralekha 1989). In contrast with the observation of Bhandari \& Chitralekha (1989) for Ranunculus sceleratus, during cellularization of the megagametophyte of Tabebuia pulcherrima the cell plates are not PAS-positive. This makes it still more difficult to follow the sequential deposition of the cell walls.

As soon as cellularization happens at the micropylar portion, the egg cell presents the nucleus at the chalazal pole, small vacuoles at the micropylar pole, and the whole cell stays in a more chalazal position relatively to the synergids, which present a bipolar vacuome and the nucleus in a central, slightly micropylar position. Such dimorphism between the synergids and the egg cell in the immature egg apparatus of T. pulcherrima contrasts with observations in other species, where the young cells of the egg apparatis are indistinguishable (Bhandari \& Chitralekha 1989, Huang \& Russell 1992).

Usually, in mature embryo sac, the common walls among the synergids, the egg cell and the central cell (chalazal portion of the egg apparatus) are very thin, discontinuous or totally absent. In this last case, only the plasmalemma delimits the cells (Cocucci \& Jensen 1969, Jensen 1972, Kapil \& Bhatnagar 1981, Willemse \& van Went 1984, Folsom \& Cass 1990, Mansfield et al. 1991, Russell 1992, Huang \& Russell 1992). The total or partial absence of cell walls in the chalazal portion of the egg apparatus is important for double fertilization, as the male gametes released by the pollen tube inside one of the synergids need to be transferred, one to the egg cell and another to the central cell. Moreover, according to Mansfield et al. (1991), the absence of cell walls in that area allows the free translocation of nutrients from synergids to egg cell and central cell. In T. pulcherrima these cell walls become very thin, but they persist until the maturity of the embryo sac and no discontinuity was observed. In Epidendum scutella (Cocucci \& Jensen 1969), Papaver nudicaule (Olson \& Cass 1981) and Scilla sibirica sato (Bhandari \& Sachdeva 1983) the cells of the egg apparatus are entirely involved by PAS-positive walls. Tilton (1981) equally observed continuous walls around the egg apparatus of Ornithogalum caudatum in some optical preparations. In Epidendrum scutella, in the chalazal portion of the degenerative synergid, common walls between egg and central cells are dissolved, so that the last two cells establish direct contact with the degenerative synergid (Cocucci \& Jensen 1969). In Capsella bursa-pastoris the cell walls are also continuous in the chalazal region of the egg apparatus, but frequently a pore is observed in the walls between the degenerative synergid and the egg cell in fertilized megagametophytes (Schulz \& Jensen 1968). This 
indicates that the presence of cell walls is not necessarily in contradiction with the fusion of the gametes (Willemse \& van Went 1984, Mansfield et al. 1991).

Together, the synergids, the egg cell and the central cell constitute what it has been denominated as female germ unit (Dumas et al. 1984, Huang \& Russell 1992). This unit has been considered the minimum group of cells capable of: (1) receive the pollen tube, (2) propitiate the discharge of the sperm cells inside the receptive portion of the female gametophyte, and (3) undergo double fertilization. In the mature embryo sac of Tabebuia pulcherrima the synergids are longitudinally elongated, with a sharp micropylar end and an enlarged chalazal portion. Only the distal portion of the synergid lateral walls is in direct contact with the embryo sac envelope (synergids and egg cell are hooked). Such features were also observed in the synergids of other Bignoniaceae (Mauritzon 1935, Swamy 1941, Govindu 1950, Gathak 1956, Davis 1966, Mehra \& Kulkarni 1985, Johri et al. 1992). The shape of the egg cell is similar to the synergids, but in Tabebuia rosea, Stereospermum chelonoides and Dolichandrone falcata a spherical shape for the egg cell was reported (Mehra \& Kulkarni 1985). Both the synergids and the egg cell present an accentuated degree of polarity. Cytoplasmic polarity of the egg cell seems to be an almost universal character in the angiosperms, and may be an important factor (or even a requirement) for the subsequent development of the zygote (Mansfield et al. 1991).

With the exception of Plumbago and other genera of the Plumbaginoideae, with no synergids in the embryo sac, in angiosperms the pollen tube penetrates one of the synergids - usually the one that started to undergo a degenerative process - through the filiform apparatus (Schulz \& Jensen 1968, Jensen 1972, Kapil \& Bhatnagar 1981, Willense \& van Went 1984). In Tabebuia pulcherrima the egg cell assumes a lateral disposition and is slightly chalazal in relation to the synergids; consequently it does not establish direct contact with the micropylar channel. Therefore the pollen tube necessarily has to find the apex of the synergids and the filiform apparatus when penetrating the micropyle.

Many ultrastructural studies have demonstrated that the synergids are very active cells, probably involved in the secretion of substances - e.g., chemiotactic substances which guide the pollen tube to the synergids, as well as in the absorption of nutritious material originating from tissues of the micropylar region and its translocation to the central and egg cells (Schulz \& Jensen 1968, Tilton 1981, Willemse \& van Went 1984, Folsom \& Cass 1990, Mansfield et al. 1991, Russell 1992, Tirlapur et al. 1993). According to this vision, the filiform apparatus exercises the important function of increasing diffusion efficiency, like wall ingrowths of transfer cells. In relation to this supposed absorptive activity, it is important to point out that, in Tabebuia pulcherrima, the cells of the integument adjacent to the micropylar ends of the synergids are very rich in starch grains. Therefore, it is suggested that the starch could be hydrolyzed and used as sources of energy for the megagametophyte.

The central cell occupies most of the embryo sac, involving at the micropylar pole the proximal two thirds of the egg apparatus and being limited at the chalazal pole by the antipodals. The cytoplasm of the central cell accumulates numerous and conspicuous amyloplasts, especially around the nuclei. The polar nuclei are quite voluminous with prominent nucleoli, containing nucleolar vacuoles. Such characters are ordinarily observed in the central cell of most of the angiosperms (Kapil \& Bhatnagar 1981, Willemse \& van Went 1984, Huang \& Russell 1992) and they indicate an intense metabolic activity, obviously associated with the function of the central cell as progenitor of the endosperm. Preliminary observations of the fertilization process reveal that the fusion of the polar nuclei occurs only after the pollen tube reaches the embryo sac. The moment in which the polar nuclei fuse with each other - prior to or after fertilization - is not constant in the angiosperms, and they never unite in some species (Tilton \& Lersten 1981).

The antipodals are very variable in the angiosperms. In Bignoniaceae the antipodals' longevity seems to vary from species to species. In all the species investigated by Mauritzon (1935) and in Bignonia megapotamica (Swamy 1941), Kigelia pinnata (Govindu 1950), Oroxilum indicum (Ghatak 1956) and Tabebuia ochracea (Bittencourt Jr. 1992) the antipodals are ephemeral, degenerating soon after cellularization of the embryo sac. However, in the species studied by Mehra \& Kulkarni (1985), as well as in Jacaranda mimosifolia, Parmentiera cerifera, Tecoma stans (Johri et al. 1992) and in the species presented here, the antipodals persist until the first developmental stages of the endosperm. The high cytoplasmatic density and the conspicuous nucleoli in the antipodals of Tabebuia pulcherrima suggest a strong metabolic activity, which is usually associated with the functions of translocation 
and secretion sometimes attributed to these cells (Jensen 1972, Kapil \& Bhatnagar 1981, Tilton \& Lersten 1981, Willemse \& van Went 1984, Mansfield et al. 1991).

During ovule ontogeny in T. pulcherrima, the nucellar epidermal cells adjacent to the sides of the embryo sac chalazal portion are not totally squashed, and a relatively thick cuticle remain on these cells. The same was observed in longitudinal sections of the ovule of T. ochracea (Bittencourt Jr. 1992). The cutinization of the embryo sac wall was observed in several species of angiosperms, both on the cells of nucellar epidermis and endothelium (Kapil \& Tiwari 1978). According to these authors, the thickness, continuity and uniformity of the cuticular layer are variable not only among species but also at different places in the same species. In the present study, no cutinization was observed in other places of the embryo sac wall. Kapil \& Tiwari (1978) pointed out that the cutinized and often thickened walls of the endothelium at the side of the nucellus and embryo sac supposedly prevent the movement of digestive endothelium synthesized enzymes into nucellar cells or embryo sac, as well as the possible outflow of solutes from embryo sac. Due to the specific local of cutinization on the outer periclinal cell walls of the chalazal remnant nucellar epidermis in Tabebuia, we agree with its role in preventing lateral flow of substances (perhaps even nutrients) into the embryo sac at these region. This barrier could be responsible for restraining the megagametophyte lateral expansion at the chalazal region.

In conclusion, the mature megagametophyte organization in Tabebuia pulcherrima is strictly determined by the patterns of vacuolation, nuclear migration, spindle orientation and cellularization. Young synergids and egg cell are quite dimorphic immediately after the megagametophyte cellularization, contrasting with the attempted generalization in literature (Bhandari \& Chitralekha 1989, Huang \& Russell 1992). The PAS-positive common walls between synergids, egg and central cell are present in the mature embryo sac, and we suggest the formation of some kind of passage for the sperm cell nuclei through these walls in fertilized megagametophytes, as related for Epidendrum scutella (Coccucci \& Jensen 1969) or for Capsella bursa-pastoris (Schulz \& Jensen 1968). Our data together with other studies on the megagametophyte development suggest that several embryological features are common for all the Bignoniaceae, specially the Polygonum type megagametophyte development, the micropylar end swelling of the megagametophyte and its absorption of the surrounding nucellar epidermis and endothelial cells, differentiation of a hypostase and presence of hooked synergids in the mature embryo sac. However, at least the shape of the mature egg cells and longevity of the antipodals seem to diverge in different species of this family.

Acknowledgments - We would like to thank Coordenação de Aperfeiçoamento de Pessoal de Nível Superior (CAPES), for grant support to the first author, and Conselho Nacional de Desenvolvimento Científico e Tecnológico (CNPq), for the research grant to the second. We also thanked the two anonymous reviewers for the critical reading and valuable suggestions for the manuscript, and Dr Julie H. A. Dutilh for English review.

\section{References}

BHANDARI, N.N. \& CHITRALEKHA, P. 1989. Cellularization of the female gametophyte in Ranunculus sceleratus. Canadian Journal of Botany 67:1325-1330.

BHANDARI, N.N. \& SACHDEVA, A. 1983. Some aspects of organization and histochemistry of the embryo sac of Scilla sibirica sato. Protoplasma 116:170-178.

BITTENCOURT JR., N.S. 1992. Anatomia floral de Tabebuia ochracea (Cham.) Standley (Bignoniaceae): histologia, vascularização e ontogenia com especial referência ao desenvolvimento do óvulo e da antera. Monografia de graduação, Universidade Federal de Minas Gerais, Belo Horizonte.

BITTENCOURT JR., N.S. \& MARIATH, J.E.A. 2002. Ovule ontogeny of Tabebuia pulcherrima Sandwith (Bignoniaceae): megasporogenesis and integument development. Revista Brasileira de Botânica 25:103-115.

CASS, D.D., PETEYA, D.J. \& ROBERTSON, B.L. 1985. Megagametophyte development in Hordeum vulgare. I. Early megagametogenesis and nature of cell wall formation. Canadian Journal of Botany 63:2164-2171.

COCUCCI, A.E. \& JENSEN, W.A. 1969. Orchid embryology: the mature megagametophyte of Epidendrum scutella. Kurtziana 5:23-38.

DAVIS, G.L. 1966. Systematic embryology of the angiosperms. John Wiley \& Sons, New York.

DUGGAR, B.M. 1899. On the development of the pollen grain and the embryosac in Bignonia venusta. Bulletin of the Torrey Botanical Club 26:89-105.

DUMAS, C., KNOX, R.B., McCONCHIE, C.A. \& RUSSEL, S.D. 1984. Emerging physiological concepts in fertilization. What's New in Plant Physiology 15:17-20.

FOLSOM, M.W. \& CASS, D.D. 1989. Embryo sac development in soybean: ultrastructure of megasporogenesis and early megagametogenesis. Canadian Journal of Botany 67:2841-2849. 
FOLSOM, M.W. \& CASS, D.D. 1990. Embryo sac development in soybean: cellularization and egg apparatus expansion. Canadian Journal of Botany 68:2135-2147.

GALATI, B.G. \& STRITTMATTER, L.I. 1999. Ovule ontogeny and megasporogenesis in Jacaranda mimosifolia D. Don. (Bignoniaceae). Phytomorphology 49:67-74.

GHATAK, J. 1956. A contribution to the life history of Oroxylum indicum Vent. Proceedings of the Indian Academy of Science B 43:72-87.

GOVINDU, H.C. 1950. Studies in the embryology of some members of Bignoniaceae. Proceedings of the Indian Academy of Science B 32:164-178.

HUANG, B.Q. \& RUSSELL, S.D. 1992. Female germ unit: organization, isolation, and function. International Review of Cytology 140:332-293.

JENSEN, W.A. 1972. The embryo sac and fertilization in angiosperms. Harold L. Lyon Arboretum Lecture 3:1-32.

JOHRI, B.M., AMBEGAOKAR, K.B. \& SRIVASTAVA, P.S. 1992. Comparative embryology of angiosperms. v. 2. Springer-Verlag, Berlin.

KAPIL, R.N. \& BHATNAGAR, A.K. 1981. Ultrastructure and biology of female gametophyte in flowering plants. International Review of Cytology 70:291-341.

KAPIL, R.N. \& TIWARI, S.C. 1978. The integumentary tapetum. The Botanical Review 44:457-490.

MANSFIELD, S.G., BRIARTY, L.G. \& ERNI, S. 1991. Early embryogenesis in Arabidopsis thaliana. I. The mature embryo sac. Canadian Journal of Botany 69:447-460.

MAURITZON, J. 1935. Etwas über die Embryologie der Bignoniaceen. Botaniska Notiser 1935:60-77.

MEHRA, K.R. \& KULKRANI, A.R. 1985. Embryological studies in Bignoniaceae. Phytomorphology 35:239-251.
NEWCOMB, W. 1973. The development of the embryo sac of sunflower Helianthus annuus before fertilization. Canadian Journal of Botany 51:863-878.

OLSON, A.R. \& CASS, D.D. 1981. Changes in megagametophyte structure in Papaver nudicaule following in vitro placental pollination. American Journal of Botany 68:1333-1341.

RUSSEL, S.D. 1992. Double fertilization. International Review of Cytology 140:357-388.

SCHNARF, K. 1931. Vergleichende Embryologie der Angiospermen. Gebrüder Borntraeger, Berlin.

SCHULZ, S.R. \& JENSEN, W.A. 1968. Capsella embryogenesis: the synergids before and after fertilization. American Journal Botany 55:541-552.

SWAMY, B.G.L. 1941. Contributions to the life history of Bignonia megapotamica. Journal of the Indian Botanical Society 20:299-305.

TILTON, V.R. 1981. Ovule development in Ornithogalum caudatum (Liliaceae) with a review of selected papers on angiosperm reproduction. IV. Egg apparatus structure and function. New Phytologist 88:505-531.

TILTON, V.R. \& LERSTEN, N.R. 1981. Ovule development in Ornithoglum caudatum (Liliaceae) with a review of selected papers on angiosperm reproduction. III. Nucellus and megagametophyte. New Phytologist 88:477-504.

TIRLAPUR, U.K., VAN WENT, J.L. \& CRESTI, M. 1993. Visualization of membrane calcium and caumodulin in embryo sacs in situ and isolated from Petunia hybrida L. and Nicotiana tabacum L. Annals of Botany 71:161-167.

WILLEMSE, M.T.M. \& VAN WENT, J.L. 1984. The female gametophyte. In Embryology of angiosperms (B.M. Johri, ed.). Springer-Verlag, Berlin, p.159-196. 